\title{
Mathematical modelling of rainfall runoff from small catchments of the northwest coast of the Black Sea
}

\author{
Maryna Moniushko, Maria Daus, Maryna Zakharova \\ Odessa State Environmental University, 15 Lvovskaya Street, 65016 Odessa, Ukraine, e-mail: Monuyshko@yandex.ua, \\ daus_maria@mail.ru,marina.od@i.ua
}

\begin{abstract}
This article is devoted to the use of a mathematical model of a flood runoff for calculating rainfall runoff hydrographs from small catchments of the northwest coast of the Black Sea. The described model was tested and applied for the following catchments located in various geographical conditions, with various amounts of initial data: experimental catchments in Zacarpathian, the northwest of the Black Sea region - Ukraine and the Republic of Moldova, small catchments of the northern part of Vietnam, etc. This work was carried out on the basis of Moldavian Water-Balance Station databases. The development of a complex approach to a mathematical simulation of the formation of the processes of rain floods from small catchments is also given further investigation in this article. A brief description of the structure of a flood runoff spatial model from small catchments then provided. As well as this, the advantages of using radiolocation measurement of rainfall in the mathematical modeling of the formation of a flood runoff are shown. The results of construction runoff hydrographs confirm the possibility of applying this spatial model with the use of radar information. The optimization of model parameters was made with the data of 123 floods. The values of the quality criterion $S / \sigma$ turned out not to exceed the value 0.8 in $81 \%$ of the considered cases of floods.
\end{abstract}

Keywords: spatial model, radar data, ground data, rainfall, discharge, runoff, hydrograph

Submitted 15 April 2014, revised 5 December 2014, accepted 13 May 2015

\section{Introduction}

Usual hydrometeorological information is selective by nature. It cannot envelop the territory of a researched catchment of a river with continuous measurement data, therefore the outcome of modelling based on such information cannot be satisfactory. It is necessary to use hydrodynamics models, taking into account distribution effective factors on the catchment in hydrology - this is because of the growing requirements regarding the quality of calculations and predictions of a river runoff. On the one hand, one of the basic advantages of such models is the presence of the spatial data module. On the other hand, practically, the calculation and prediction of river runoff with these models have limited application because of the lack of rigorous information about the field of rainfall. Therefore, the distance measurements of rainfall have essential advantages when compared with the conventional ones (Ivanenko 2007). One reliable method of the determining of spatial distribution of rainfall is radiolocation measurement (Jakubiak et al. 2014); for instance, there is a meteorological locator in Hungary that covers almost all the territory of the Ukrainian Carpathians. Another way of defining rainfall fields is to use of satellite data. In this case, the radar complex in Moldova was used for calculating of flood runoff hydrographs. Its measurements have a spatial character and operative data retrieval. However, the graduation of the radar measuring complex represents essential difficulties because of the lack of a direct mode of a measurement of rainfall on area, which is something that should be accepted as standard. The same circumstance hampers a direct evaluation of the exactness of rainfall measurement by the modern radar method. The main purpose of this paper is to show, through a concrete example, the advantages of such an approach in comparison with the conventional one.

\section{Used data}

Materials from the Moldavian Water-Balance Station (MWBS) were used in this work. This station is situated on the territory of the catchment of the Balcata River that belongs to the lower part of the basin of the Dniester River (Fig. 1). The Balcata River has many small inflows and their main characteristics are given in Table 1.

The experiment's catchment, the Sagaydachny brook, with an area 3.92 sq. km, was equipped with a self-recording rain gauge, and this gauge provided data of runoff of several catchments of the northwest coast of the Black Sea, with an area between 179 and 1210 sq. km. These catchments were in operative range of a radar-measuring complex in Kotovsk (Moldova). The complex included 


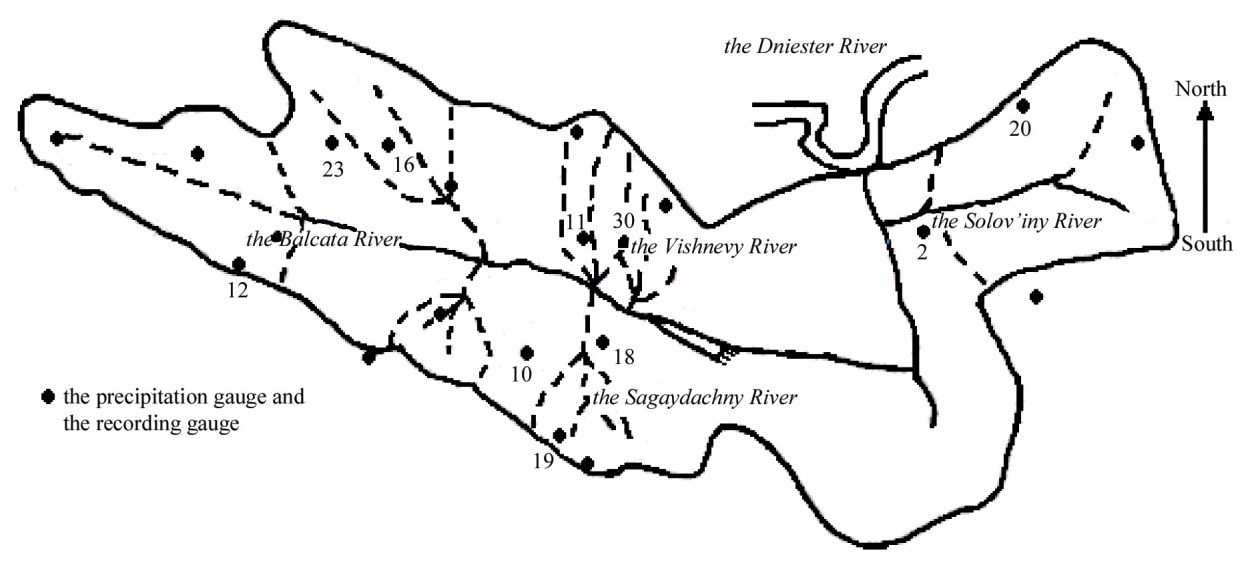

Fig. 1. Scheme of Moldavian Water-Balance Station (MWBS)

Table 1. Basic characteristics of the catchment of the Balcata River

\begin{tabular}{|l|c|c|c|c|c|}
\hline \multicolumn{1}{|c|}{ Name of the River } & $\begin{array}{c}\text { Area } \\
{\left[\mathrm{km}^{2}\right]}\end{array}$ & $\begin{array}{c}\text { Length of } \\
\text { the river } \\
{[\mathrm{km}]}\end{array}$ & $\begin{array}{c}\text { Average Height } \\
\text { of the catchment } \\
{[\mathrm{m} \text { a.s.1.] }}\end{array}$ & $\begin{array}{c}\text { Average slope } \\
\text { of the river } \\
{[\%]}\end{array}$ & $\begin{array}{c}\text { Average slope } \\
\text { of the catchment } \\
{[\%]}\end{array}$ \\
\hline the Balcata River & 62.4 & 16.0 & 140 & 10.6 & 104 \\
\hline the Vishnevy River & 4.22 & 4.2 & 120 & 33.8 & 98.7 \\
\hline the Sagaydachny River & 3.92 & 2.1 & 150 & 39.5 & 136 \\
\hline the Solov'iny River & 23.6 & 8.7 & 120 & 9.3 & 42.9 \\
\hline
\end{tabular}

the radar of MRL-2 system - special "Osadky" equipment. This complex was allowed to measure the intensity of atmospheric precipitation within a radius of $100 \mathrm{~km}$ around the centre every $5 \mathrm{~min}$., and to represent it in actual time scale as a digital map of average rainfall intensity on meshes with the areas of 4 and $100 \mathrm{sq}$. km for some intervals of time. This allowed the reception of the information necessary for the construction of the runoff shaping mathematical model from Sagaydachny catchment and other areas of the northwest coast of the Black Sea.

\section{Model description}

There are now enough studies devoted to simulation of the processes reproducing natural systems to the scale of river basin - and these have been tested on real catchments and used for the solution of practical tasks.

Among them are the well-known models, which were worked out at the Water Problem Institute of the Russian Academy of Science (the system of physical and mathematical models of WPI) (Kuchment, Gelfan 1993), Institute of Limnology (ILCM) (Kondratyev 2007), Ukrainian Hydrometeorological Institute (modeling complex "Flood" with involvement of module LEVEL_TS_M) (Ischuk et al. 2002); the model of European Hydrological Model System (SHE) (Beven 1988); the model of small catchments, which was worked out by the service of research works USDA (SWAM); the topography-based hydrological model TOPMODEL (Beven 1996); the model with distributed parameters of the British Institute of
Hydrology (IHDM); and the kinematic model of water flow and erosion (KINEROS2) (Smith 1995).

The unique technique of the flood hydrograph calculation was offered in the works of Ivanenko (1983, 1986). It is based on the solution of a set of equations of water balance for the separate segments of the riverbed for the calculated interval of time $\Delta t$ in view of side water inflow from slopes to the river channel. The optimum size of the calculated interval $\Delta t$ is established from a condition of satisfactorily detailed elaboration of the flood hydrograph calculation and the required exactness of its ordinates. The side inflow of water from slopes is calculated on a separate quotient to squares area, located along the isochrones - the lines connecting the points on the catchments with an identical distance from the closing basin. The quotient square has the form of a quadrate with a leg equal to the distance the water passes on the channel for a calculated interval of time with current velocity in the location of a segment. As a result, all catchments areas are divided into parts, the size of which depends on the time and on length of the river in connection with the modification of current water velocity.

The operator for the evaluation of flood ordinates is:

$$
Q_{j, i}=\sum_{i=1}^{j}\left[v_{j, i} B\left(x_{g}\right) R_{j, i} \Delta t \overline{q_{l}}\left(x_{g}\right)\right]
$$

where $Q_{j, i}$ is the discharge through the lower line of $i$-th segment in the extremity of $j$-th interval of time $\Delta t, \mathrm{~m}^{3} \mathrm{~s}^{-1}$; $v_{j, i}$ is the current water velocity in the limits of the considered segment and the interval of time $\left(\mathrm{m} \mathrm{s}^{-1}\right)$, computed 
using the following formula, which was created by Ivanenko (1983, 1986):

$$
v_{j, i}=a_{p}\left(\frac{1+L}{1+l_{i}}\right)^{0,25} I_{j}^{0.3} Q_{j, i}^{0.3}
$$

where $a_{p}$ is an empirical parameter of a channel which depends on it roughness and the form of cross-section; $L$ is the overall length of the river, $\mathrm{m} ; l_{i}$ is the length of a channel from drain up to a considered segment, $\mathrm{m} ; I_{j}$ is the average slope of a channel on the $j$-th segment.

The average overland inflow was estimated on its values on the segments situated on an isochrones:

$$
\overline{q_{l}}\left(x_{g}\right)=\frac{1}{n_{g}} \sum_{k=1}^{n_{g}} q_{l}\left(x_{g}, y_{k}\right)
$$

Here $n_{g}$ is the amount of segments on a specific isochrones for which the intensity of overland inflow within $l$-th time unit $q_{l}$ was determined; $y_{k}$ is the distance on an isochrones from one of the catchment divisions up to the $k$-th segment of the intensity overland flow definition, $\mathrm{m}$.

Thus, the primary factor variable on the catchment areas - overland flow - is used in this model. It corresponds to the actual conditions of rainfall flood formation.

As the research shows, a surface type of a runoff from slopes predominates in the considered region. Therefore, the water yield intensity average for separate quadrate coordinates $\left(x_{g, i}, y_{k}\right)$ was calculated using this formula:

$$
h_{i}\left(x_{g, i}, y_{k}\right)=a_{i}\left(x_{g, i}, y_{k}\right)-I_{i}\left(x_{g, i}, y_{k}\right)
$$

Here $h_{i}\left(x_{g, i}, y_{k}\right), a_{i}\left(x_{g, i}, y_{k}\right)$ and $I_{i}\left(x_{g, i}, y_{k}\right)$ are accordingly the water yield intensity, the intensity of the rain, the intensity of the absorption referred to the $k$-th interval of time, $\mathrm{mm} \min ^{-1}$.

The calculation of average intensity of overland flow for the considered single square is conducted with the account of the rainfall established for this segment, and the preceding humidifying and geomorphological factors.

The surface flow module was calculated using the following formula (Ivanenko 1983, 1986):

$$
q_{i}\left(x_{g, i}, y_{k}\right)=16.67 \frac{U\left(x_{g, i}, y_{k}\right)}{\bar{U}\left(x_{g, i}, y_{k}\right)} \overline{h_{g}}\left(x_{g, i}, y_{k}\right)
$$

$U\left(x_{g, i}, y_{k}\right)$ is the current velocity of water on the slope in this formula, $\mathrm{m} \mathrm{s}^{-1} ; \bar{U}\left(x_{g, i}, y_{k}\right)$ is the average velocity for the previous time lag, $\mathrm{ms}^{-1} ; \bar{h}_{g}\left(x_{g, i}, y_{k}\right)$ is the water yield intensity average for the previous time lag, $\mathrm{mm} \mathrm{min}^{-1}$.

The velocity of overland flow was calculated using the following formula, created by Befany (1958):

$$
U\left(x_{g, i}, y_{k}\right)=a_{c}\left[I_{s l}\left(x_{g, i}, y_{k}\right) \bar{h}\left(x_{g, i}, y_{k}\right) l_{s l}\left(x_{g, i}, y_{k}\right)\right]^{0.33}
$$

Here $I_{s l}$ is the slope; $l_{s l}$ is the length of slopes, $\mathrm{m} ; a_{c}$ is the parameter. All elements of the formula refer to a quadrate with coordinates $\left(x_{g, i}, y_{k}\right)$.

For soil water balance calculation, a submodel of a water condition, founded on the known equation of Richards, was constructed (Daus 1989; Ivanenko et al. 2006):

$$
\frac{\partial \theta}{\partial t}=\frac{\partial}{\partial z}\left[D(\theta) \frac{\partial \theta}{\partial z}-K(\theta)\right]-S_{k}(\theta, z)
$$

where $\theta$ is the humidity of soil; $D(\theta), K(\theta)$ is the association of diffusivity and the factor of filtration with humidity; $S_{k}(\theta, z)$ is the intensity of soil humidity modification at the expense of moisture absorption by a root system.

The numerical method of the solution of this equation is realized in view of initial and boundary conditions (Daus 1989). The greatest complexity arises with the representation of the entry conditions on profiles of humidity on elementary catchment sites. In further calculations there is no such information for other catchments. Therefore, as the average entry conditions, long-term data of moisture stores by the beginning of spring were used; this makes 0.8 from magnitude the minimum moisture-holding capacity.

The dependences of the diffusivity and the factor of soil filtration with humidity were set by the empirical relations:

$$
\begin{aligned}
& D(\theta)=D_{0}\left(\theta-\theta_{m g}\right)^{\alpha} \\
& K(\theta)=K_{0}\left(\theta-\theta_{m g}\right)^{\beta}
\end{aligned}
$$

where $\theta_{m g}$ is the maximum hygroscopic of soil; and $D_{0}, K_{0}$, $\alpha, \beta$ are empirical parameters.

The value of the quality criterion $\bar{S} / o$ is calculated using the following formula (Befany et al. 1983):

$$
\bar{S}=\sqrt{\frac{\sum_{i=1}^{N}\left(Q_{o b s_{i}}-Q_{c a l_{i}}\right)^{2}}{N}}
$$

where $\bar{S}$ is the root-mean-square error for checking calculation; $Q_{o b s_{i}}$ is the observed discharge of flood for the $i$-th interval of time; $Q_{\mathrm{cal}_{i}}$ is the calculated discharge of flood for the $i$-th interval of time; $N$ is the number of terms of the series:

$$
\sigma=\sqrt{\frac{\sum_{i=1}^{N}\left(Q_{o b s_{i}}-\bar{Q}_{o b s}\right)^{2}}{N}}
$$

where $\sigma$ is the root-mean-square deviation of the observed discharges of flood from the average value of the observed discharge. 


\section{Results of a model application}

The selection of model parameters was made with the data of 123 floods, measured in basin MWBS on the Sagaydachny and Vishnevy catchments in the period 1980-1986. The quality of the parameter selection shows a criterion $S / \sigma$, which in $81 \%$ of cases has not exceeded the value 0.8 .

The Sagaydachny catchment is represented by a system of 4 squares, with size $2 \times 2 \mathrm{~km}$; Catchments of other rivers of the region are represented by systems of three (the Kogilnik River in Kotovsk town) up to 13 (the Botna River in Kaushani town) squares, with size $10 \times 10 \mathrm{~km}$.

The average slope in the direction of surface runoff was defined, and the schematization of the types of soils in correspondence with the maximum percentage of the area occupied by a particular kind of soil was made within the limits of each squares. The hydrophysical parameters of the soils were taken into account according to their developments, as described in the work of Daus (1989).

Research connected with the use of radar materials concerning precipitation in mathematical modeling first of all raise the problem of the adequacy of rainfall field exposure to the area covered by radar. This problem is covered fairly explicitly in the work of Ivanenko at al. (1989). It can now be remarked that the check of the adequacy of rainfall radar fields' exposure consisted of the comparison of a rainfall field's statistical performance, as obtained for a controlled territory with the help of radar and ground measurements. MWBS, where the density of a web of selfrecording rain gauges is on average 1.3 rain gauges per 10 sq. km, was chosen as the controlled territory station. The probability curves of rainfall were constructed by using the ground data and the radar. The results turned out to agree with each other well. The ratio of the average layer of rainfall over the area obtained with the help of radar, and the appropriate value obtained from the data from the ground web of self-recording rain gauges for liquid rainfall with an average area rainfall intensity of $1 \mathrm{~mm} \mathrm{hour}^{-1}$ and over is between the limits of 0.91 to 1.10 , and the coefficient of the correlation of average rainfall layers on segments of 4 sq. km, obtained with the help of the radar and ground modes of measurements, was 0.71-0.90.

The information mentioned above allow for a conclusion as to a satisfactory exactness of rainfall measurement by radar, and the possibility of its use for flood hydrograph calculating.

As an illustration to what is stated above, we can consider some examples of the calculation of a flood resulting from the rain with the help of the considered spatial model of shaping runoff on the Sagaydachny catchment.

The results of radar measurement of rainfall for seven separate rains in April-June 1984 were used in the first variant. The ground data for the same phase of observations obtained with the help of a web self-recording rain gauge were used in the second variant.

The calculated and actual discharges of the Sagaydachny catchment with the use of ground and radartracking data are compared in Table 2. In this table, the following symbols are used: $\Delta Q / Q_{0}$ is the relation of the maximum calculated and actual discharge expressed in percentage, and $\Delta W / W_{0}$ is the relation of calculated and actual volumes of a flow.

The comparison of the hydrographs designed according to the two variants with actual ones obtained through observational data of the Sagaydachny catchment shows that the outcomes of calculations are similar. However, the radar gives a slightly overstated result, in terms of maximum discharge of water - at 1.66-29.91 (Table 2), and also the discharges of water in a phase of a flood fall; also, as a rule, the maximum discharge of flood described by the radar materials occurs earlier than the actual flood peak. The volumes of floods described by the radar are also greater than the actual ones, though the estimated criterion $S / \sigma$ for six of seven calculated floods show satisfactory values (Table 2).

The standard hydrograph obtained with this model is represented in Fig. 2.

Table 2. Comparison of the calculated and actual discharge on Sagaydachny catchment with the use of ground and radar rainfall data

\begin{tabular}{|c|c|c|c|c|c|c|c|}
\hline \multirow{2}{*}{ No. } & \multirow{2}{*}{ Date } & \multicolumn{3}{|c|}{ From the rain gauge } & \multicolumn{3}{c|}{ From the radar } \\
\cline { 3 - 8 } & $\begin{array}{c}\Delta Q / Q_{0} \\
{[\%]}\end{array}$ & $\Delta W / W_{0}$ & $S / \sigma$ & $\begin{array}{c}\Delta Q / Q_{0} \\
{[\%]}\end{array}$ & $\Delta W / W_{0}$ & $S / \sigma$ \\
\hline 1 & 18.04 .1984 & -9.67 & 0.84 & 0.68 & 24.67 & 0.96 & 0.60 \\
\hline 2 & 27.04 .1984 & 6.14 & 0.79 & 0.76 & 16.04 & 1.28 & 0.67 \\
\hline 3 & 28.04 .1984 & -11.03 & 1.02 & 1.23 & 15.08 & 1.21 & 1.11 \\
\hline 4 & 14.05 .1984 & 24.57 & 1.07 & 0.63 & 29.91 & 1.34 & 0.68 \\
\hline 5 & 22.05 .1984 & 3.21 & 0.96 & 0.59 & 12.00 & 1.37 & 0.53 \\
\hline 6 & 08.06 .1984 & 8.63 & 1.12 & 0.69 & 1.66 & 1.48 & 0.70 \\
\hline 7 & 25.06 .1984 & 14.06 & 1.19 & 0.61 & 7.01 & 1.83 & 0.79 \\
\hline
\end{tabular}




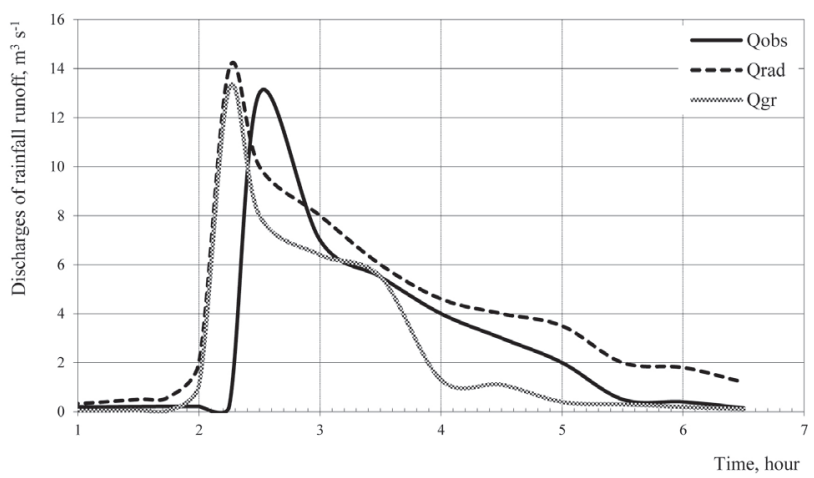

Fig. 2. Runoff hydrographs on the Sagaydachny catchment, 22 May 1984 (key: 1 - an actual hydrograph; 2 - a calculated hydrograph with the use of the radar precipitation data; 3 - a calculated hydrograph with the use of the ground precipitation data)

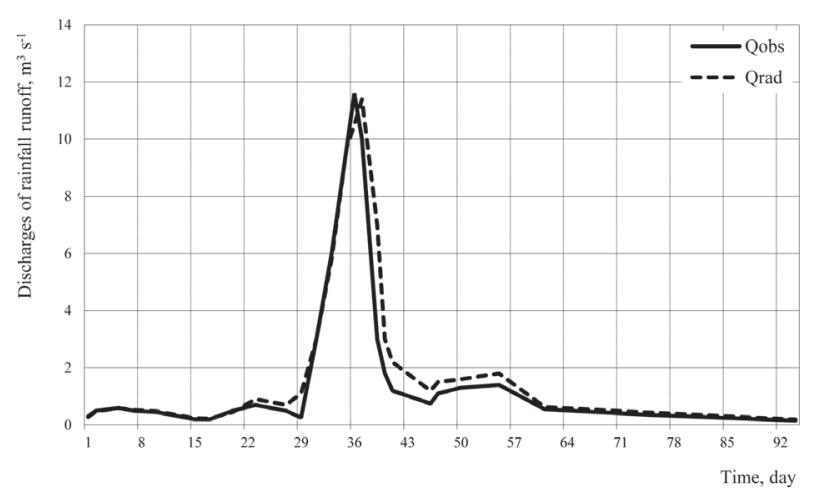

Fig. 3. Runoff hydrographs during the warm season on the Kogilnik River (Kotovsk town), 1985

As the comparative calculations were made for the Sagaydachny catchments, where 4 self-recording rain gauges are available, there is one in each mesh of the radar grid, and therefore some divergence in the outcomes of flood calculation data between radar and ground measurements can be explained by the high spatial dynamics of shower rainfall in the considered region, and also by the fact that the optimization of the model parameters on the ground data is not reliable enough.

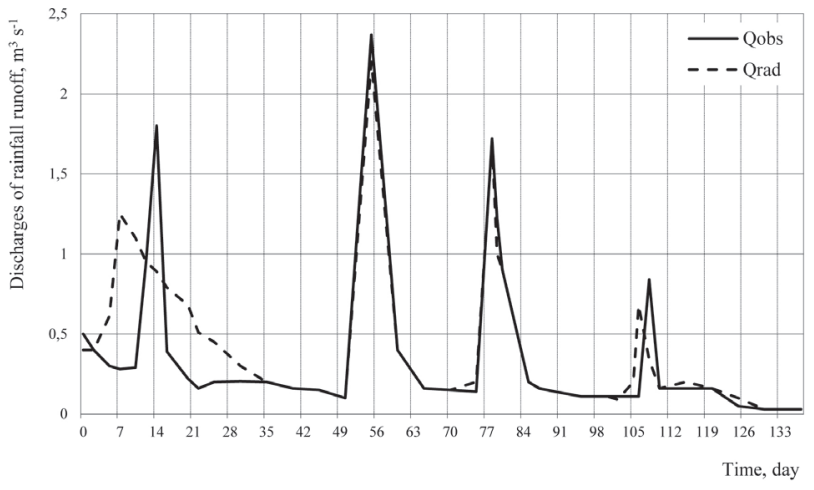

Fig. 4. Runoff hydrographs during the warm season on the Lunga River (Ceadar-Lunga town), 1985 (key: 1 - an actual hydrograph; 2 - a hydrograph calculated with the use of radar precipitation data)

At the following stage, the given model trial hydrographs were calculated during a warm phase of year on small catchments of the region, the areas of which varied changed from 179 up to 1210 sq. km. The actual hydrograph and the one created through the rainfall obtained by the radar complex are shown in Fig. 3 and 4.

The outcomes of the comparison of actual and calculated hydrographs on other catchments are given in Table 3 .

The analysis shows that the calculated hydrographs during a warm phase of a year correspond to the course of the actual one. A parameter $S / \sigma$ for six designed hydrographs gives $0.53-0.79$, and for three - it exceeds 0.8 (Table 3).

The described model was tested and applied for the following catchments located in various geographical conditions, with various amounts of initial data: experimental catchments in Zacarpathian (Zakharova 2008b), the northwest of the Black Sea region (Ukraine) (Ivanenko et al. 2006) and Moldavian territory (the Republic of Moldova) (Ivanenko, Daus 1989; Ivanenko, Zakharova 2003), small catchments of the northern part of Vietnam, etc.

Table 3. Comparison of calculated and observed runoff hydrographs according to the radar measurements for small catchments of the northwest coast of the Black Sea

\begin{tabular}{|c|c|c|c|c|c|c|}
\hline \multirow[t]{2}{*}{ No } & \multirow[t]{2}{*}{ River - Point of observation } & \multirow[t]{2}{*}{ Year } & \multicolumn{2}{|c|}{$\begin{array}{c}\text { Maximum of } \\
\text { flow } \\
{\left[\mathrm{m}^{3} \mathrm{~s}^{-1}\right]}\end{array}$} & \multirow[t]{2}{*}{$W_{\text {rad }} / W_{\text {obs }}$} & \multirow[t]{2}{*}{$S / \sigma$} \\
\hline & & & $Q_{\text {obs }}$ & $Q_{\mathrm{rad}}$ & & \\
\hline 1 & the Yalpuh River - Budzhak town & 1984 & 19.6 & 13.0 & 0.94 & 0.62 \\
\hline 2 & the Yalpuh River - Budzhak town & 1985 & 2.08 & 2.02 & 0.92 & 0.74 \\
\hline 3 & the Lunga River - Ceadar-Lunga town & 1984 & 2.37 & 2.20 & 0.98 & 0.64 \\
\hline 4 & the Lunga River - Ceadar-Lunga town & 1985 & 1.81 & 1.59 & 0.93 & 0.79 \\
\hline 5 & the Large Salcha River - Musayit town & 1984 & 1.43 & 1.26 & 0.81 & 1.12 \\
\hline 6 & the Kogilnik River - Kotovsk town & 1984 & 10.3 & 9.07 & 0.89 & 0.91 \\
\hline 7 & the Kogilnik River - Kotovsk town & 1985 & 11.6 & 11.4 & 1.12 & 0.79 \\
\hline 8 & the Botna River - Kaushani town & 1984 & 9.43 & 7.42 & 0.72 & 0.86 \\
\hline 9 & the Botna River - Kaushani town & 1985 & 21.5 & 19.1 & 0.96 & 0.53 \\
\hline & average & & & & 0.92 & 0.77 \\
\hline
\end{tabular}




\section{Brief conclusion}

1) It should be noted that the outcomes of the comparison of the actual and the obtained hydrographs produced with the use of either radiolocation or ground data describe a satisfactory exactness of calculation.

2) The satisfactory exactness of the radar rainfall measurement was evaluated by the coefficients of correlation between layers of rainfall measured in these two ways, and which varied from 0.71 to 0.90 .

3) The process of optimization was conducted on the basis of 126 floods that occurred on the territory MWBS; in the results, it was found that the quality criterion $S / \sigma$ did not exceed the value 0.8 in $81 \%$ of cases.

4) The quality criterion $S / \sigma$, calculated for the other small catchments of the northwest coast of the Black Sea, varied from $0.53-0.79$ in six cases, and it did not exceeded 0.8 in three only cases.

5) The given calculations were carried out on the basis of limited amounts of information, therefore they can only be considered preliminary. However, they allow for the conclusion that the application of a spatial model with the use of radar information is basically acceptable for the evaluating of hydrographs on insufficiently known catchments of the northwest coast of the Black Sea.

Bibliography

Befany A.N., 1958, Bases of the theory of a storm flow (in Russian), Proceedings of the Odessa Hydrometeorological Institute, 14 (2), 311

Befany N.F., Kalinin G.P., 1983, Exercises and Methodological Developments in Hydrological Forecasts (in Russian), Hydrometeopublishing, $384 \mathrm{pp}$.

Beven K., 1988, The models with distributed parameters. Hydrogeological Forecasting, M.G. Anderson, T.P. Bert, World, 497-533

Beven K., 1996, Topmodel: a critique, Hydrological Processes, 11 (9), 1069-1085, DOI: 10.1002/(SICI)10991085(199707)11:9<1069::AID-HYP545>3.0.CO;2-O

Daus M.E., 1989, Calculation of the parameters of soil humidity equations based on the data of artificial rainfall for the territory of the Black Sea Western Coast (in Russian), deposited in VNIIHMI-MCD, 903-gm89
Ischuk O.O., Obodovs'kii O.G., Konovalenko O.S., 2002, The interaction of GIS and the problem-oriented modeling complex in the systems of forecasting and assessment of the impact of emergencies related to floods (in Ukrainian), Hydrology, Hydrochemistry and Hydroecology, 3, 53-59

Ivanenko A.G., 1983, Calculation of a rainfall runoff hydrograph taking into account a dynamic of velocity lag and an overland runoff (in Russian), Proceedings of the Ukrainian Hydrometeorological Institute, 194, 32-41

Ivanenko A.G., 1986, Rain flood computation on the basis of the account of factors of field runoff (in Russian), Water Resources, 4, 38-46

Ivanenko A.G., 2007, Mathematical Modelling of Hydroecological Systems (in Ukrainian), Ecology, 144 pp.

Ivanenko A.G., Daus M.E., Konareva L.N., 1989, Calculation of rainfall field based on the data of Kotovsk radar complex (MWBS) (in Russian), Deposited in VNIIHMI-MCD, 947gm89

Ivanenko A.G., Daus M.E., Zakharova M.V., 2006, Modelling a rain flash and chemical runoff from small watersheds of the north-west part of the Black Sea (in Ukrainian), Black Sea Ecological Bulletin, 3-4, 113-119

Ivanenko A.G., Zakharova M.V., 2003, Kinematic model of runoff water and chemical substances (in Russian), Meteorology, Climatology and Hydrology, 47, 168-178

Jakubiak B., Szturc J., Ośródka K., Jurczyk A., 2014, Experiments with three-dimensional radar reflectivity data assimilation into the COAMPS model, Meteorology, Hydrology and Water Management, 2 (1), 43-54

Kondratyev S.A., 2007, Formation of External Loading on Water Bodies: The issues of Simulation (in Russian), Science, 253 pp.

Kuchment L.S., Gelfan A.N., 1993, Dynamic-Stochastic Models of Formation of River Flow (in Russian), Science, 104 pp.

Smith R.E., Goodrich D.C., Woolhiser D.A., Unkrich C.L., 1995, A kinematic runoff and erosion model, Computer Models of Watershed Hydrology, 697-732

Zakharova M.V., 2008a, Estimation of exactness of calculations of flow hydrographs based on the method of water balances and the model of kinematic wave (in Ukrainian), Ukrainian Hydrometeorological Journal, 3, 197-201

Zakharova M.V., 2008b, Modelling of the processes of runoff water on the small catchments of the Ukrainian Carpathians (in Ukrainian), Herald of the Hydrometeorological Center of the Black and Azov Seas, 4 (8), 106-112 